\title{
Comparative characteristics of varieties of winter rye according to the number of flowers in spikelets and grain yield
}

\author{
Starychenko V. ${ }^{1}$, Huba I. ${ }^{2}$ \\ NSC «Institute of Agriculture of NAAS» \\ 2b Mashynobudivnykiv Str., Chabany, Kyiv-Sviatoshyn region, Kyiv oblast, 08162, Ukraine \\ e-mail: ${ }^{1}$ cereal. iz@naas.gov.ua, ${ }^{2}$ Airin 777@ukr.net \\ ORCID: ${ }^{1} 0000-0002-4551-8263,{ }^{2} 0000-0002-9339-0217$
}

Goal. To conduct a comparative analysis of conventional and multi-flower winter rye according to productive characteristics, fruit formation, and grain yield to determine the potential of the use of multi-flower rye in selection. Methods. The study was carried out during 2014-2017 in NSC «Institute of agriculture NAAN» on gray forest soils of the Northern part of Forest-Steppe. The object of research -common rye (Secale vulgare Koern.) and its multi-flower varieties with more flowers in the spikelets of an ear - Secale triflorum, tetraflorum, pentaflorum and 2 natural multi-flower species - Secale var. compositum Lam. and Secale var. monstrosum Koern. Results. Comparative structural analysis of multi-flower rye with the usual 2 -flowers winter rye. The increase in the number of 3rd and 4th fertile flowers in the spikelets of an ear positively influenced grain weight in an ear and plant, without reducing significantly the weight of 1000 grains. Rye that formed 5th flower in a spikelet, had a lower performance as to the ear grain content and performance, that was significantly inferior to conventional 2-flower and multi-flower (3 and 4) forms of rye. Conclusions. It is established that in each of many varieties laid a different number of flowers in spikelets that positively and negatively affect fruit formation and grain productivity of winter rye. Natural multi-flower varieties of winter rye are valuable sources of multi-flower ability with the highest number of flowers per ear, but the smallest grain size and lowest indices of grain productivity.

Key words: var. compositum Lam. var. monstrosum Koern., multi-flower ability, fertility, selection.

DOI: https://doi.org/10.31073/agrovisnyk202005-04

The source material is the main guarantee for creating modern high-yielding varieties. The high degree of affinity in the world collection of varieties is a limiting factor for further increasing the productivity of crops. Accordingly, for hybridization it is necessary to select and use new combinations of crosses, the parents for which were selected from collection of samples that can guarantee the improvement of a particular trait. In rye, multiflowering is practically unexplored and there are almost no data on the influence of multiflowering on the spike productivity and the nature of its inheritance in general.

Environmental conditions significantly affect on the selection of valuable genotypes by grain yield and quantitative traits in general. Most researchers believe that the use of unique forms in crosses that have more spikelets, flowers and grains can be one of the ways to increase the productivity of cereals [1-3]. V.S. Arbuzova and others, in their breeding work with soft wheat, placed great emphasis on the study of multiflowering [4-6].

However, the degree of manifestation of the sign of multiflowering is under the influence of the environment [7, 8]. Moreover, the genotype-environment interaction has a significant impact on the phenotypic manifestation of the multiflowering. Survival of additional flowers (more than two per spikelet) significantly depends on water balance and lighting, nutrient content in the soil (I-IV stages of organogenesis) and temperature factors - the sum of active temperatures from tillering to flowering and photosynthetic activity of leaves and spikes during the growing season [9]. In ordinary varieties of rye in the germinal spikelet of rye is laid 5-6 flowers, but usually develop two, rarely three, and the rest atrophy [6].

One of the ways to increase the yield of winter rye is to create varieties and lines that can set a full three or more grains in a spikelet. The main problem of growing multiflorous varieties is the fine-grainedness and poor threshing of additional flowers, as well as the high instability of the manifestation of the trait of multiflowering, which is highly dependent on environmental conditions. Our work focuses on the study of multiflorous specimens of winter rye, which not only form additional flowers, but also set the grain from them. The new varieties contain three-graining spikelets, and some new breeding numbers - mainly four-graining spikelets in the spike [10].

The aim of this work is to select and characterize the elements of the spike structure of winter rye samples, which cover the whole spectrum of rye diversity by the number of flowers in the spikelets and spike and determine the possibility of using them in breeding to create breeding material with genetically determined 
multigraining and high penetrance of this trait. Potentially, four-graining samples may have a sufficiently high penetrance.

Materials and methods. The research was conducted during 2014-2017 in the northern part of the Forest-Steppe of Ukraine. As the material was used 20 winter rye samples from breeding and collection nurseries with different manifestations of the trait of multiflowering, and two natural varieties as a source of the trait of multiflowering - var. compositum Lam. and var. monstrosum Koern. The control for comparison was the usual two-flowered variety Pamiat Khudoierka. Structural analysis of plants on the following indicators: plant height, productive tillering, length of the main spike, number of spikelets in the main spike, number of flowers in the main spike, number of grains from the main spike, percentage of kernels in the main spike, grain weight from the main spike and the weight of 1000 kernels. 30 plants were taken from each sample. The main spike was analyzed, because on other spikes the genetically determined multiflowering was less phenotypically manifested. Basic statistics methods using programs "Excel" and "Statistica" were used for data analysis.

Results. According to a number of investigations, in addition to the usual type (two-flowered rye) Secale vulgare Koern. and multi-flowered natural varieties of winter rye, namely Secale var. compositum Lam. and Secale var. monstrosum Koern., there are also intermediate multi-flowered forms that differ in the formation of different numbers of flowers in the spikelets. These are three-flowered (triflorum), four-flowered (tetraflorum) and five-flowered (pentaflorum) rye, although six-flowered rye is sometimes found $[11,12]$.

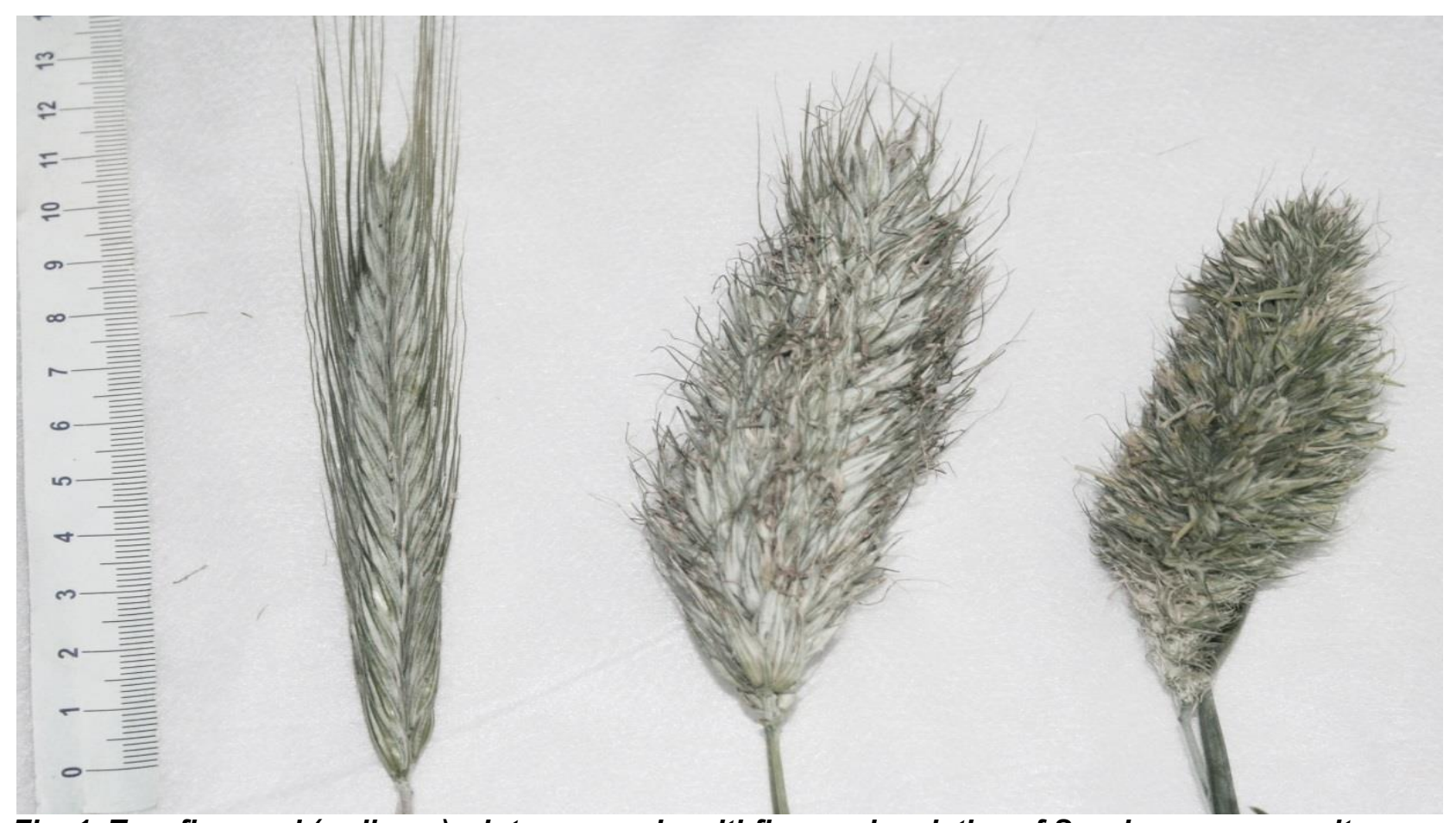

Fig. 1. Two-flowered (ordinary) winter rye and multi-flowered varieties of Secale var. compositum Lam. and Secale var. Koern

That is, there are intermediate forms that can be arranged in the scheme in the following sequence: Secale sereale L .: Secale vulgare Koern. $\rightarrow$ Secale triflorum P. Beavn. $\rightarrow$ Secale tetraflorum $\rightarrow$ Secale pentaflorum $\rightarrow$ Secale var. compositum Lam. $\rightarrow$ Secale var. monstrosum Koern. We selected and analyzed samples that belong to all known forms. In fig. 1 shows the extreme variants on the basis of "the number of flowers in the spikelet", from the two-flowered sample to the variety monstrosum, where the spikelets are much smaller and placed so tightly that it complicates their calculation. In fig. 2, 3 show the spikelets and spikes of intermediate variants in comparison with the control. It is seen that in multi-flowered forms not all spikelets have the same number of flowers. The form is determined by the maximum number of formed flowers in the spikelets. 


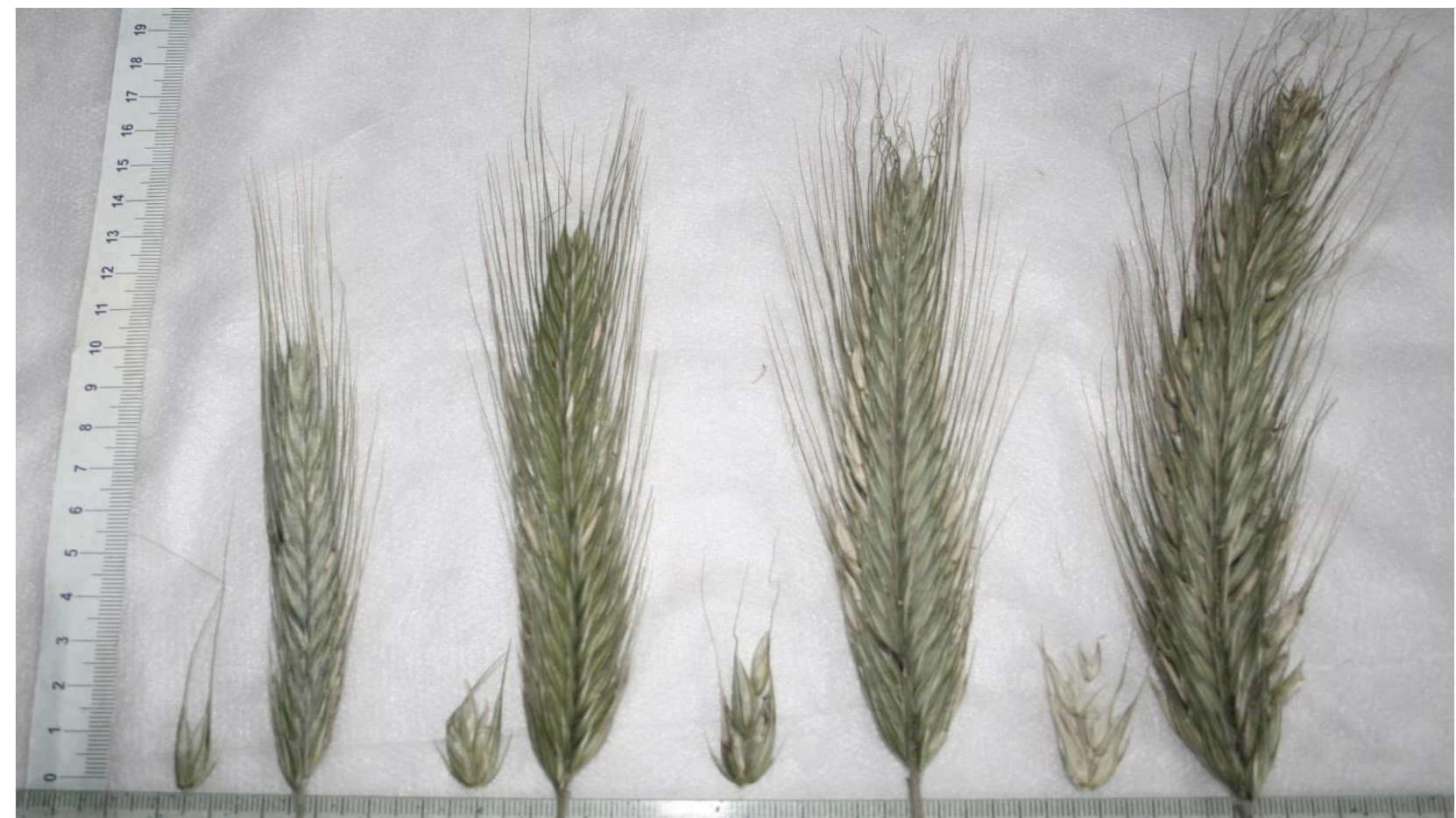

Fig. 2. Two-flowered, three-flowered, four-flowered and five-flowered spikes of winter rye

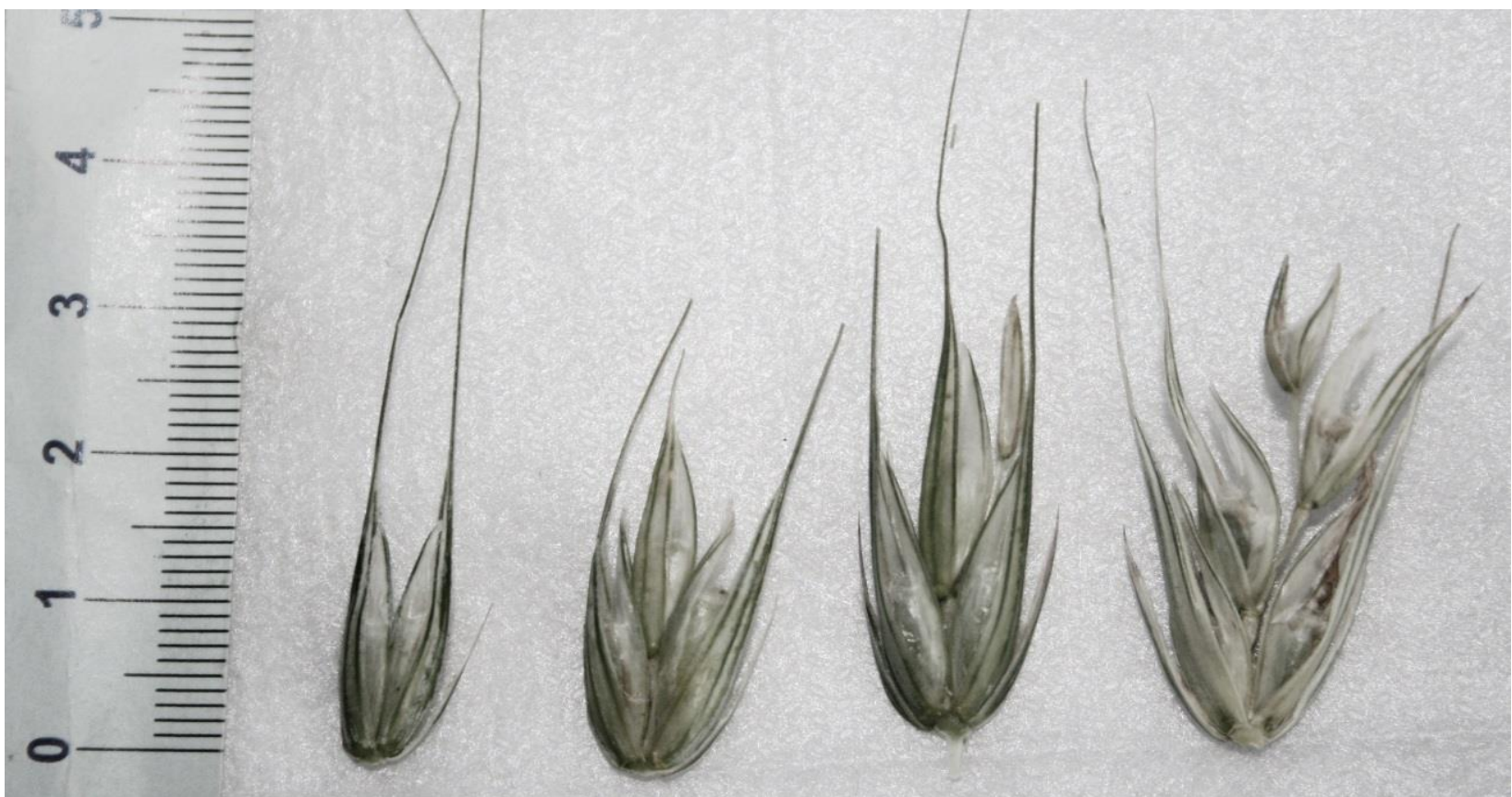

Fig. 3. Two-flowered, three-flowered, four-flowered and five-flowered spikelets of winter rye

In fig. 4 shows a comparative analysis of the forms of rye on some economically valuable features and elements of the structure of the spike. In fig. $4 \mathrm{a}$ and $4 \mathrm{c}$ were used to construct a histogram of the trait "number of flowers in the spike" value $\times 10^{-1}$. 


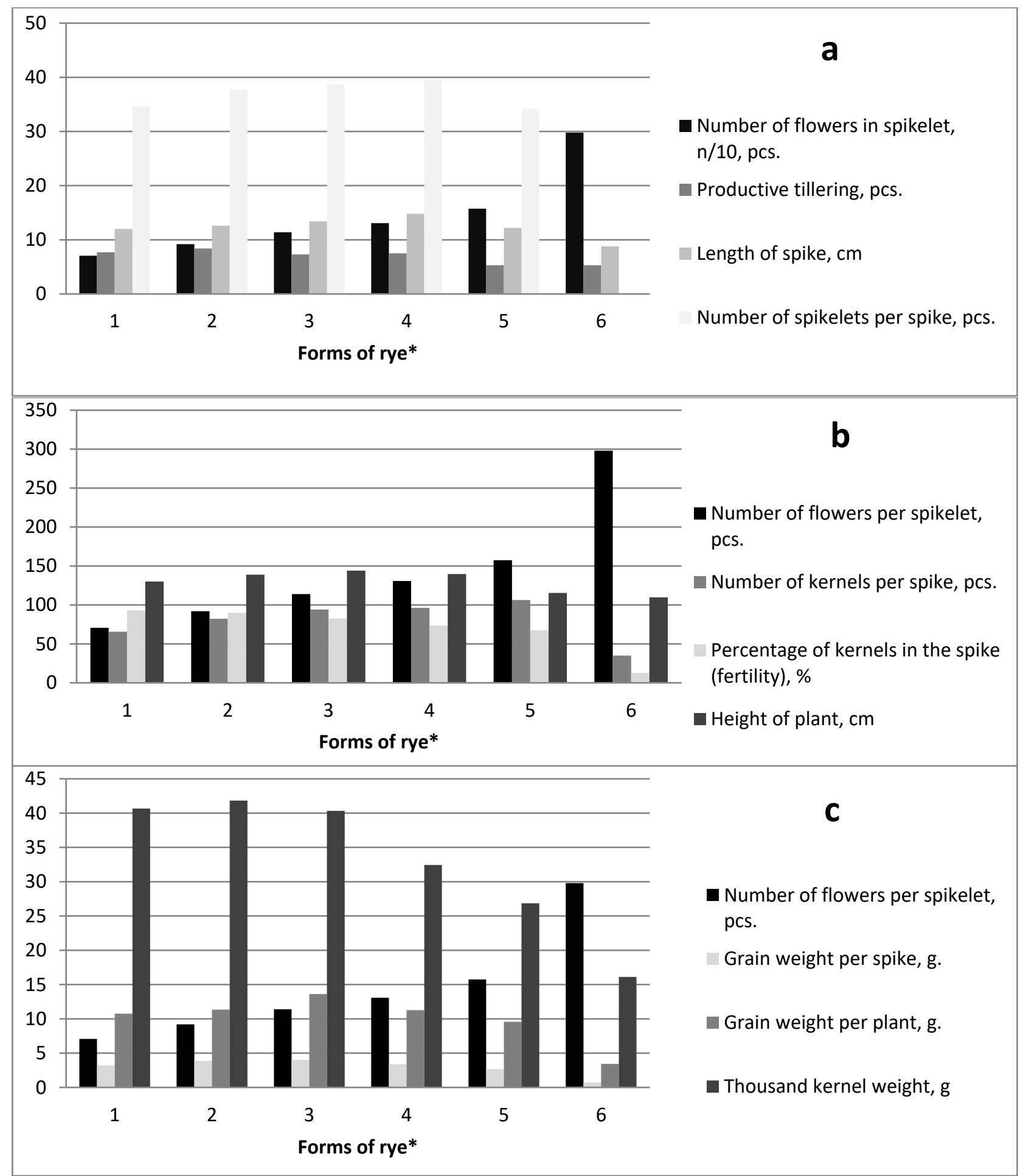

Fig. 4. Comparative characteristics of winter rye forms by elements of plant structure and grain productivity ${ }^{1}$. The given values differ significantly in forms at $p<0.05$ (according to Student). *Forms marked: 1 - Secale vulgare Koern. (2-flowered, St.), 2 - Secale triflorum P. Beavn. (3-flower), 3 Secale tetraflorum (4-flower), 4 - Secale pentaflorum (5-flower), 5 - Secale var. compositum Lam., 6 - Secale var. monstosum Koern

As a control trait, the number of flowers per spike was chosen, which varies significantly depending on the form of the rye. In fig. 4a shows the productive tillering, the length of the main spike and the total number of spikelets in the main spike. The length of the spike of almost all multi-flowered varieties is $0.2-2.8 \mathrm{~cm}$ longer than the standard, but in the variety var. monstrosum Koern. the length was on $3.2 \mathrm{~cm}$ less than the standard $(12.0 \mathrm{~cm})$. The largest number of spikelets per spike was in the five-flowered -39.5 pcs. and fourflowered rye -38.7 pcs. In three-flowered rye, the average number of spikelets per spike was 37.7 pcs., which is on 3.1 pcs. more than the standard - two-flowered rye (34.6 pcs.). In the variety of var. monstrosum Koern. the number of spikelets in the spike due to the too dense form of the spike was not counted. 
In fig. $4 \mathrm{~b}$ is shown a comparative analysis of plant height, the total number of flowers formed in the main spike, the total number of grains per main spike and the percentage of grain in the main spike (fertility). It was found that the highest height have 4-flowered rye $-144.1 \mathrm{~cm}$, and five-flowered $-139.7 \mathrm{~cm}$, which is $14.1 \mathrm{~cm}$ and 9.7 respectively higher than ordinary two-flowered rye $(130.0 \mathrm{~cm})$, and the lowest height has plants var. monstrosum Koern. $-109.7 \mathrm{~cm}$. The smallest number of formed flowers per spike has a twoflowered standard -70.7 pieces. with the largest fertility $-93.0 \%$. The largest number of flowers per spike has a multi-flowered variety var. monstrosum Koern. -298.0 pieces, but with scanty fertility - only $12.7 \%$. Three-flowered and four-flowered rye are slightly inferior to the fertility of the main spike of the standard 89.8 and $82.5 \%$, respectively.

Comparison of productivity is shown in fig. 4c. Three-, four- and five-flowered plants have a higher mass of grain from the main spike (table 3 ) than standard two-flowered rye $(3.21 \mathrm{~g})-3.87,4.03$ and $3.38 \mathrm{~g}$, respectively. The variety var. compositum Lam. is inferior in terms of grain weight per spike $(2.67 \mathrm{~g})$. Grain weight per plant in three-, four- and five-flowered rye is slightly higher than the standard $(10.75 \mathrm{~g})-11.35 \mathrm{~g}$, 13.62 and $11.27 \mathrm{~g}$.

The multi-flowered variety var. monstrosum Koern. has a meager mass of grain per spike and per plant $0.73 \mathrm{~g}$ and $3.44 \mathrm{~g}$, respectively. The highest TKW is in three-flowered rye, on average $41.82 \mathrm{~g}$, which is 1.15 $\mathrm{g}$ higher than the standard. The TKW decreases with a further increase in the number of seeds, ie, in fourflowered $-40.33, \mathrm{~g}$, in five-flowered $-32.43 \mathrm{~g}$, in the variety var. compositum Lam. $-26.85 \mathrm{~g}$ and $16.11 \mathrm{~g}$ in the variety var. monstrosum Koern.

Obviously, the form of rye is related to the number of flowers, the number of seeds and other characteristics. The Tau Kendall correlation coefficient was used to calculate the dependence of plant structure elements on the variety, which allows correlations to be established between qualitative and quantitative traits. As a qualitative trait, the form of rye was considered in this case, ie the standard number of flowers per spikelet for a certain sample, with the appropriate gradations: Secale vulgare Koern. (2flowered), Secale triflorum P. Beavn. (3-flower), Secale tetraflorum (4-flower), Secale pentaflorum (5-flower), Secale var. compositum Lam. and Secale var. monstrosum Koern. 23 quantitative signs with continuous variability were considered as quantitative (table).

The form of rye has the strongest effect on the total number of formed flowers, the number of third, fourth flowers and the number of grains from them. Also, the trait affects the overall fertility of the spike, the coefficient is about -0.6. On the positive side, the grain weight of the first two flowers and the TKW are weakly dependent on the increase or decrease in the number of flowers in general, so we can not be afraid of a critical decrease in the values of these traits when using multi-flower samples.

Correlation (according to Kendall) between form of rye and other traits. *Marked correlations are significant at $p<0,05$

\begin{tabular}{|c|c|c|c|}
\hline \multirow{2}{*}{ Pairs of variables } & \multirow{2}{*}{$\begin{array}{c}\text { Coefficient } \\
\text { of correlation } \\
\text { Kendall } \\
\text { Tau } \\
\end{array}$} & \multirow{2}{*}{\begin{tabular}{c|}
$\begin{array}{c}\text { Standard } \\
\text { deviation }\end{array}$ \\
$Z$
\end{tabular}} & \multirow{2}{*}{$\begin{array}{c}\text { Probability } \\
\text { level }\end{array}$} \\
\hline & & & \\
\hline Form \& Height of the plant, $\mathrm{cm}$ & 0,28523 & 1,75830 & 0,07870 \\
\hline Form \& Productive tillering, pcs & 0,28523 & 1,75830 & 0,07870 \\
\hline Form \& Length of spike, $\mathrm{cm}$ & $0,45122^{*}$ & 2,78153 & 0,00541 \\
\hline Form \& Spikelets per spike, pcs & $0,57680^{*}$ & 3,55566 & 0,00038 \\
\hline Form \& Spike density (pc. per $10 \mathrm{~cm}$ ) & 0,29791 & 1,83644 & 0,06629 \\
\hline Form \& Thickness of the 2nd internode, mm & 0,21781 & 1,34270 & 0,17937 \\
\hline Form \& Length of the upper internode, $\mathrm{cm}$ & $-0,22185$ & $-1,36756$ & 0,17145 \\
\hline Form \& Total number of formed flowers, pcs. & $0,71625^{*}$ & 4,41528 & 0,00001 \\
\hline Form \& Total number of grains per main spike, pcs. & $0,64019^{*}$ & 3,94640 & 0,00008 \\
\hline Form \& Total spike fertility, $\%$ & $-0,58948^{*}$ & $-3,63381$ & 0,00028 \\
\hline Form \& Total number of 2nd flower, pcs. & $0,57680^{*}$ & 3,55566 & 0,00038 \\
\hline Form \& Number of grains per 2nd flower, pcs. & $0,41200^{*}$ & 2,53976 & 0,01109 \\
\hline Form \& Total number of 3rd flower, pcs. & $0,70731^{*}$ & 4,36014 & 0,00001 \\
\hline Form \& Number of grains per 3rd flower, pcs. & $0,72005^{*}$ & 4,43870 & 0,00001 \\
\hline Form \& Number of 4 th flower, pcs. & $0,71437^{*}$ & 4,40365 & 0,00001 \\
\hline Form \& Number of grains per 4th flower, pcs. & $0,65220^{*}$ & 4,02045 & 0,00006 \\
\hline Form \& Weight of grains per 2 flowers, $g$ & $-0,17938$ & $-1,10575$ & 0,26883 \\
\hline Form \& Weight of grains of 3 flowers, $g$ & $0,71110^{*}$ & 4,38352 & 0,00001 \\
\hline
\end{tabular}




\begin{tabular}{|l|r|r|r|}
\hline Form \& Weight of grains of 4 flowers, g & $0,65220^{*}$ & 4,02045 & 0,00006 \\
\hline Form \& Weight of grains of 5 flowers, g & $0,33492^{*}$ & 2,06458 & 0,03896 \\
\hline Form \& Weight of grain per main spike, g & $0,32326^{*}$ & 1,99273 & 0,04629 \\
\hline Form \& Weight of grain per plant, g & $0,57680^{*}$ & 3,55566 & 0,00038 \\
\hline Form \& Weight of 1000 kernels, g & 0,05705 & 0,35166 & 0,72509 \\
\hline
\end{tabular}

\section{Conclusions}

It was found that increasing the number of the third and fourth grained flowers in the spikelets has a positive effect on the weight of grain per spike and per plant, while not significantly reducing the weight of 1000 kernels. Rye, which has an additional fifth flower in the spikelet, has lower rates, both in terms of spike fertility and grain productivity, which is significantly inferior to three-flowered, four-flowered and ordinary twoflowered rye. A strong inverse correlation was found between the number of flowers per main spike and the spike fertility. That is, the greater the number of flowers in the spikelets and the spike in general, the smaller the number of formed kernels. Natural multi-flowered varieties - var. compositum Lam. and var. monstrosum Koern., which have the largest number of flowers due to the significant branching of the spikelets in the spike, have the lowest spike fertility and the lowest grain productivity. Therefore, for breeding to increase the number of grains in the spikelet, it is advisable to use four-grain samples, but varieties var. compositum Lam. and var. monstrosum Koern. are better to be used for investigation the genetics of multiflowering.

\section{References}

1. Sreenivasulu, N., \& Shcnurbusch, T. (2012). A genetic playground for enhancing grain number in cereals. Trends Plant Sci, 17(2), 91. https://doi.org/10.1016/j.tplants.2011.11.003.

2. Martinek, P., \& Bednar, J. (1988). Gene resources with non-standard spike morphology in wheat. Proc. Int. 9th Wheat Genet. Symp., Saskatoon, Canada, 286-288.

3. Wang, Y., Miao, F., \& Yan, L. (2016). Branching Shoots and Spikes from Lateral Meristems in Bread Wheat. PLOS ONE 11(3), e0151656. https://doi.org/10.1371/journal.pone.0151656.

4. Arbuzova, V. S., Efremova, T. T., Martinek, P., Chumakova, E. V., \& Dobrovolskaya, O. B. (2014). Izmenchivost priznakov produktivnosti kolosa u gibridov F2, poluchennyih ot skreschivaniya sortov myagkoy pshenitsyi Novosibirskaya 67, Saratovskaya 29, PUZA-4 c mnogotsvetkovoy liniey SKLE 123-09 [Variability of signs of spike productivity in F2 hybrids obtained from crossing common wheat varieties Novosibirsk 67 , Saratov 29, PUZA-4 with the multicolor line SKLE 123-09]. Vavilov Journal of Genetics and Breeding, 18, 704-712. [In Russian].

5. Nucl, P., \& Fowler, J. (1992). Comparison of a branched spike wheat with the cultivar Neepawa and HY320 for grain yield components. Canada. J. Plant Sci., 2, 671-677. https://doi.org/10.4141/cjps92-083

6. Kobyilyanskiy, V. D. (1982) Rozh. Geneticheskie osnovyi selektsii [Rye. Genetic basis of selection]. Moscow: Kolos. [In Russian].

7. Malcomber, S. T., Preston, J. C., Reinheimer, R., Kossuth, J., \& Kellogg, E. A. (2006). Developmental gene evolution and the origin of grass inflorescence diversity. Advanced in botanical research, 44, 423-479. https://doi.org/10.1016/S0065-2296(06)44011-8.

8. Sharman, B. C. (1944). Branched head in wheat and wheat hybrids. Nature, 153, 497-498.

9. Pennell, A. L., \& Halloran, G. M. (1983). Inheritance of supernumerary spikelet in wheat. Euphytica, 32, 767-776.

10. Starychenko, V. N., Guba, I. I., \& Kobernyk, N. I. (2018). Bahatokvitkovist zernovykh kolosovykh kultur - istoriia ta stan vyvchennia [Multiflorous cereals - history and state of studies]. Plant breeding and seed production, 113, 150-167. https://doi.org/10.30835/2413-7510.2018.134368. [In Ukrainian].

11. Smirnov, V. G., \& Sosnihina, S. P. (1984) Genetika rzhi [Genetics of rye]. Leningrad: LGU. [In Russian].

12. Fedorov, V. S., Smirnov, V. G., \& Sosnihina, S. P. (1971). Nekotoryie itogi issledovaniy po chastnoy genetike rzhi [Some results of researches on special genetics of rye.] Genetics research. Leningrad, 4, 117133. [In Russian]. 